\title{
Marketing Activity in the Context of the Digital Economy
}

Submitted 02/01/19, 1st revision 05/02/19, 2nd rervision 22/05/19, accepted 20/05/19

\author{
Terenina I.V. ${ }^{1}$, Ovanesyan N.M. ${ }^{2}$, Khan R.S. ${ }^{3}$, Fedosenko A.A. ${ }^{4}$
}

\begin{abstract}
:
Purpose: The presented article aims to identify and assess the prospects of construction companies' marketing activities in the digital economy.

Design/Methodology/Approach: For the description of the construction companies marketing activities prospects in the digital economy it is necessary: first, to determine the specifics of the construction companies marketing activities; second, to assess the trends in the digital economy development in relation to the construction product promotion; third, to determine the directions of construction marketing development.

Findings: For the estimating of the construction companies' marketing activities prospects in the digital economy the basic principles of the choice of the construction product making by the target consumers have been identified, the analysis of the efforts of construction companies marketing activities and potential buyers in the digital space has been carried. The authors systematized the basic directions of the development of construction companies' marketing activities in the digital economy.

Practical Implications: The research results may be implemented into managerial practices in order to improve and increase the efficiency of construction companies' marketing activities.

Originality/Value: The main contribution of this study is the assessment of the basic trends of development of construction companies ' marketing activities in the digital economy, on the basis of which specific events of marketing policy can be implemented.
\end{abstract}

Keywords: Construction marketing, marketing in the digital economy, marketing activity.

JEL Code: M20, M31.

Paper Type: Research article in Special Issue dedicated to Russian Economy.

Section 1: Digital Economy.

${ }^{1}$ Doctor of Science (Economics), Professor of Marketing and Engineering Economics Department, Don State Technical University, Rostov-on-Don, teririn@yandex.ru

${ }^{2}$ Doctor of Science (Economics), Professor of Marketing and Engineering Economics Department, Don State Technical University, Rostov-on-Don,nmo2013@yandex.ru ${ }^{3}$ Candidate of Science (Economics), Associate Professor of Marketing and Engineering Economics Department, Don State Technical University, Rostov-on-Don, primery@rambler.ru

${ }^{4}$ Candidate of Science (Economics), Associate Professor of Marketing and Engineering Economics Department, Don State Technical University, Rostov-on-Don, ann.smaragd@gmail.com 


\section{Introduction}

The gradual relocation part of the enterprises' activities to the digital economy dictates the need to revise approaches to this activity's organization. This is especially true for those areas of business in which the consumer preliminarily, and often finally, looks for contract or through the information space of the Internet. The advantage of digital technologies is the low cost, which results in the reduction of production costs and lower prices for the end consumer. This influence is manifested in the field of enterprises' marketing activities mostly. If the transfer of marketing activities to the Internet is rather a positive thing for trade enterprises, then it is not so obvious for the construction industry. To understand how the marketing activities of construction industry enterprises are compatable with the format of the digital economy, it is necessary to consider the specifics of the construction enterprises' marketing activities and the specifics of their work in the digital economy.

Construction marketing is specific as much as construction production in comparison with other branches of human activity. So, there is a certain marketing specialization by industry, market and other objects of marketing efforts, despite the universality of marketing tools and the possibility of its use in any branch of human activity, even in those that are not directly related to the market (for example, marketing of public organizations or government institutions). In particular, the specificity of marketing in the field of capital construction is explained by the following features:

$\checkmark$ the life cycle of an investment product is usually longer than of the other industrial products, and especially consumer goods. Thus, the life cycle of a most common product of capital construction - real estate - is most often measured in a few decades;

$\checkmark$ the production cycle of construction is also characterized by a considerable duration, as an integral part of the general life cycle of its facilities. Typical for real estate is the production cycle, not measured in months, but over the years, so it is not surprising that construction is characterized by high capital intensity, which sharply limits the number of potential buyers of real estate. It is not surprising that consumer preferences in the field of capital construction are highly conservative and are not as influenced by fashion as the demand in the market for consumer goods;

$\checkmark$ the complicated organizational structure of construction enterprises, caused by the multi-level form of interaction in the internal and external environment;

$\checkmark$ a certain dualism is inherent in capital construction: so in the field of construction for production needs the product consumers seem to be more professional than buyers of end-use goods, and in terms of housing construction, a high degree of investments' riskiness leads to the necessity for well-rounded information about the consumer properties of products to buyers; 
$\checkmark$ not mass, but differentiated marketing is preferable for construction, because of the high level of needs' individualization in this area;

$\checkmark$ a significant role in customer requirements for investment products is played by the level of technology development in consumer industries. In fact, the low level of customer's technical development cannot generate demand for a high-tech investment product. And, on the contrary, the scientific and technical progress in the branches-customers of capital construction services pushes construction enterprises to improve the technology of building production;

$\checkmark$ the capital construction objects are less to be standardized, their quality is mostly determined by the level of producer's professionalism, that gives them a special value due to the authorship of the producer;

$\checkmark$ the capital construction objects are characterized by quite tight localization, i.e., placing in a certain location. Their spatial movement (especially for real estate) is practically impossible without very large costs, and even a complete loss of consumer qualities;

$\checkmark$ the process of capital construction depends much on natural and climatic conditions. In addition to the constructive, technical, environmental and economic consequences of this factor, it is necessary to take into account the seasonal fluctuations in demand for capital construction products;

$\checkmark$ the distribution channels of capital construction products have a high level of specialization, and commercial intermediation in the field of capital construction is poorly developed, especially in comparison with the market for consumer goods. In this sphere the direct contacts (zero level channels) between producers and customers are more often observed;

$\checkmark$ the specificity of marketing in the field of capital construction is determined by a variety of work performed, the feature of the product distribution and its management, the irregularity of construction and assembly works, low paying capacity of the customer and imperfect government regulation of the construction sector.

A key aspect of the successful operation of an enterprise in a digital economy is the willingness of the end customer of the company's goods and services to use modern digital technologies in search of benefits (Thalassinos \& Thalassinos, 2018). Current trends in the development of digital technologies show that the number of the global net work users will exceed 4 billion, or more than $60 \%$ of the world's population by 2020 .

In Russia, the Internet audience in 2017 reached 90 million people or $73 \%$ of the country's population. The contribution of the digital economy to Russia's GDP is $2.42 \%$ at the end of 2017. The impact of Internet markets on the economy is growing at $11 \%$ per year. The contribution of the mobile economy was $3.8 \%$ of GDP. Today, the mobile economy is the 11th largest economy in Russia, and in the next 5 years its growth is projected at $10.7 \%$ per year. The mobile economy will be larger than the agricultural sector by 2021 . 
The volume of the marketing and advertising segment amounted to 191 billion rubles in 2016; and its volume increased by $17 \%$ to 224 billion rubles in 2017 . The Internet in Russia almost reached the level of TV advertising at the end of 2017. While maintaining growth rates, the Internet will overtake TV in terms of advertising by the 2 nd half of 2018 .

The contextual advertising remains the fastest growing segment among all segments of the advertising market with dynamics about $22 \%$ per year. This trend will increase significantly in the next five years - in particular, due to the rapid growth in revenue from mobile advertising. At the same time, almost half of the total expenditure on Internet advertising will be spent on promotion by mobile devices. The mobile segment accounted for $48 \%$ of total spending on online advertising in 2017. A significant part of all expenditures on mobile advertising (almost 93\%) goes to contextual advertising in search engines - it is about 73.6 billion rubles. At the same time display advertising for mobile devices will grow more dynamically. Its volumes increased by $58 \%$ (vs. $42 \%$ of the context) and reached 5.7 billion rubles in 2017. In 2018-2019 the growth of the mobile context will become much more modest - $15 \%$ and the display in the following years will grow by $50 \%$ and $40 \%$ respectively. The most popular format of online advertising is banner; it presents in advertising campaigns $73 \%$ of advertisers. A comparable number of enterprises also use targeted advertising in social networks $(71 \%)$. The least popular are advertising in games (10\% of respondents), ads (16\% of respondents) and rich-media formats (17\% of respondents). So, advertisers use 6-7 advertising tools mostly. At the same time about a quarter of companies (27\%) use only 3 tools and fewer, and a comparable number (29\%) uses more than 8 advertising formats.

Thus, it is obvious that the shift in marketing activities to digital technology is already a well-marked trend, and it will be also manifested in construction enterprises.

\section{The role of public and private partnership (PPP) institution in attraction of financing}

The specifics of the construction enterprises' marketing activities are determined by the features of the construction products' sales process. When we consider as a product the residential objects (such as apartments, houses), we note that the process of choosing construction products by the consumer has a number of characteristics:

$\checkmark$ asignificant time required for a decision;

$\checkmark$ a large amount of the information to be analyzed;

$\checkmark$ a significant number of factors which determine the choice (location, technical characteristics, the purpose of the purchase);

$\checkmark$ a high degree of wariness in the process of making decisions related to the significance of financial costs and high level of risk; 
$\checkmark$ a significant number of indirect factors which influence the choice (mortgage rates, the possibility of residential loans'obtaining, social policy of the state, etc.).

All of the above forces a potential buyer to search and analyze a significant amount of information, and its collecting begins in the global information space. The collection of information includes the following steps:

$\checkmark$ the search for information about building in construction objects;

$\checkmark$ the objects' characteristics evaluation from the significant position for a particular consumer;

$\checkmark$ the search for information about the developer;

$\checkmark$ the assessment of the partnership desirability with a particular developer based on the collected information;

$\checkmark$ the obtaining of the information about the object from the selected companydeveloper in off line mode.

In other words, the preliminary consumer decision occurs during the analysis of the freely available information before communicating with representatives of the developer or realtors. Obviously, in such conditions, the consumer desire to continue communication with a particular developer, and the possibility for the buyer to consider a particular option depends on the quality of the available information. It is quite logical that attracting a potential buyer in this case should begin within the Internet. The specificity of the construction product determines the specifics of marketing efforts as:

$\checkmark$ the process of building is stretched in time and the beginning of sales often starts even before the moment "off plan";

$\checkmark$ a high level of risk in the construction industry requires an emphasis on the reliability of the developer.

The current state of risk management in construction is characterized by low efficiency and poor predictability, these issues were considered in the work "Cluster approach in identifying risks in supply chains" (Terenina, 2016). The features of construction products' marketing were investigated in the work of Khan andSurkov (2015), so we can enumerate such of them as:

$\checkmark$ the presence of heterogeneous market segments, geographic, economic, and psychographic;

$\checkmark$ the high riskiness of transactions in the minds of consumers due to the high capital intensity of the building product;

$\checkmark$ the need for active removal of cognitive dissonance arising from the consumer as a result of high-risk transactions; 
$\checkmark$ the need for long-term communicative impact using personal sales techniques and so on.

The set of marketing tools used by construction companies is largely determined by the high degree of consumer involvement in taking purchasing decisions (Khan and Surkov, 2017). Individualization of customer requirements leads to the development of a customer-oriented business philosophy. The direct influence of this trend on the construction requires the reduction of the investment cycle; low stock levels; high reliability in meeting delivery times; production flexibility (Terenina, 2006). Obviously, the use of marketing within the digital economy is possible both from the perspective of direct communication and feedback:

$\checkmark$ the evaluation of web queries statistics in the network allows to assess the consumer's interest in construction sites in general and in a particular object;

$\checkmark$ the inclusion of a small questionnaire into the site structure of a construction company allows to obtain a potential buyer profile, and, depending on the questions posed, can determine the characteristics the consumer is looking for in a real estate;

$\checkmark$ the customers' appeals through the company's website create another feedback channel, which allows, in a certain extent, to remove cognitive dissonance after purchase.

The use of Internet communication channels allows construction companies:

$\checkmark$ to create an image of a reliable developer due to the quality websites of the company itself and the building under construction objects;

$\checkmark$ to provide potential buyers with the maximum comprehensive information about the object's characteristics by the graphic images and photographs;

$\checkmark$ to involve the buyer into the process of virtual inspection of a potential apartment, stimulating him to make a purchase;

$\checkmark$ to inform buyers about the progress of construction by the online broadcast from cameras located on the construction site. It has a positive effect on the investment risk assessment by consumer and allows the construction to sell the real estate object before its commissioning;

$\checkmark$ the use of a particular object's sales statistics in conjunction with the certain sales techniques allows the developer to motivate the buyer to conclude the transaction as soon as possible.

\section{Results}

The analysis of the construction enterprises' marketing activities in the digital space shows that over 1,230 construction organizations are represented in the city of Rostov-on-Don, and over 1110 of them are engaged in the real estate construction. Meanwhile only $60 \%$ of construction companies have their own website on the Internet. 
At the same time, the analysis of web queries statistics by categories related to the construction enterprises and building under construction objects information (Figure 1) showed that, on average, 1.755 .392 hits per month fall in the category "housing complexes", of which the category "housing complex site" takes 1.150 .026 hits. And the number of requests related to the purchase of an apartment amounted over than 3.631.850 per month, and the search for developers' sites is 1.767.535, for construction companies' sites is 295.472 hits per month. Requests for reviews of housing complexes amounted to 243.772 hits per month.

Figure 1. Analysis of web queries statistics by categories related to the construction companies and built/building under construction objects

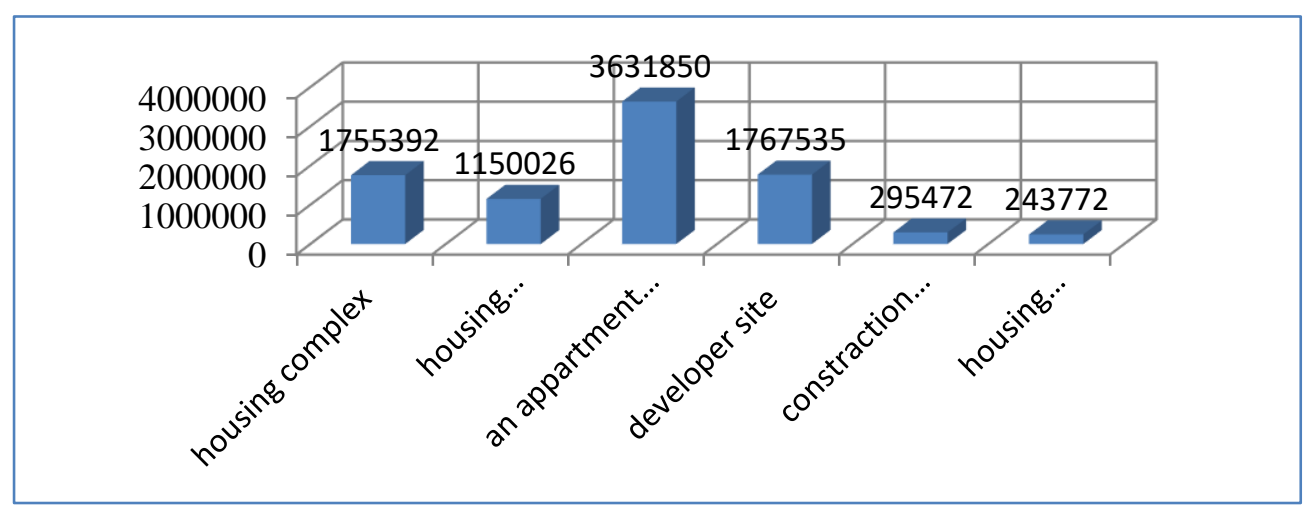

The analysis of the web queries dynamics for individual categories shows the following points (Figure 2):

$\checkmark$ in the category "developer site", the number of requests increased over than 2.5 times from September 2016 to August 2018;

$\checkmark$ in the category "housing complex site", the number of requests increased over than 39\% from September 2016 to August 2018;

$\checkmark$ in the category "housing complex reviews", the number of requests increased over than 57\% from September 2016 to August 2018.

It is also necessary to note the obvious increase in the number of requests made through mobile channels. It indicates the need to develop such kind of a format for construction enterprises' and residential complexes' websites that would allow marketing communications to be implemented within mobile applications. Thus, the question arisesas follows: whether the significant advantages of marketing in digital space mean that a construction enterprise can completely abandon other marketing costs and completely switch to marketing efforts on the Internet.

Obviously, construction enterprises will not be able to abandoncompletely the traditional offline communication channels with the consumer. And this primarily owes to the features of the construction object: in particular, it is mandatory to place 
the information boards indicating the developers, deadlines for the object, etc. at the building site. It is a common practice to place banners with photos and/or plans of the building under constructionobject on the fences enclosing the building site, as well as placing advertising banners on the facade of the object.

Figure 2. Web queries dynamics analysis for individual categories (construction companies and housing complexes) through the 2016-2018.

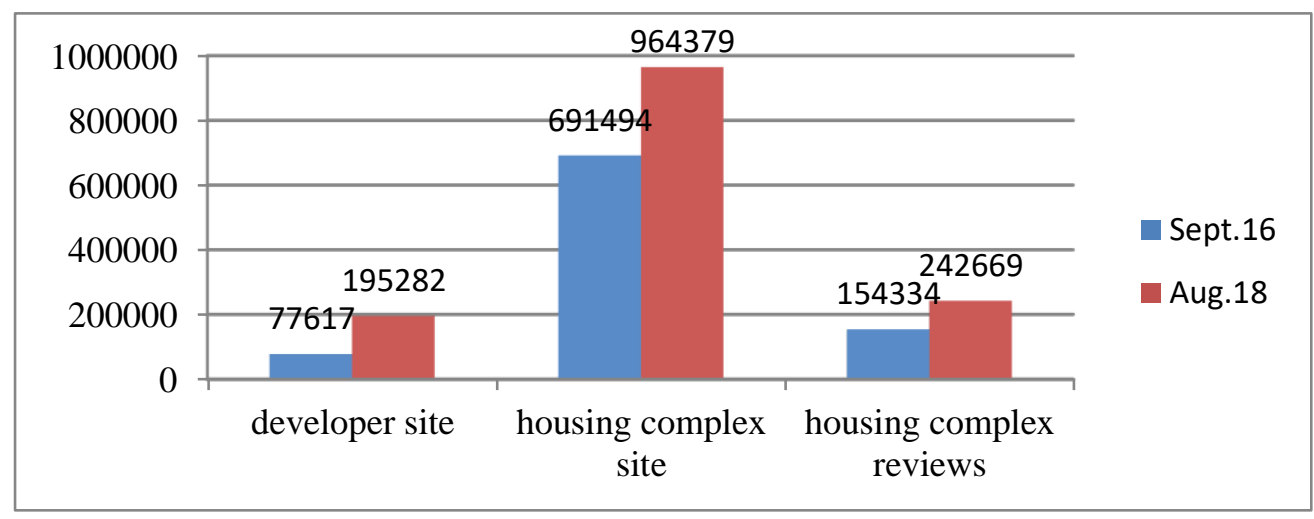

The necessity of the construction company's reputation maintaining is directed to the creation of a favorable organization image and at removing cognitive dissonance from customers. So it requires the use of public relations tools, including the press, which takes a certain level of expenditure on media publications. One of the basic sales tools of construction product is personal sales, i.e., direct contact between the seller and the buyer. And there are several reasons for it:

$\checkmark$ firstly, it is about the specifics of construction products, with the real estate objects domination. And these objects have a number of characteristics that should be clearly demonstrated to the buyer;

$\checkmark$ secondly, it is about the features of the construction process, in particular, the long period of the process, which requires the constant contact with the buyer to maintain his confidence in the decision;

$\checkmark$ thirdly, it is about the importance of consumer capital investment, which leads to increased awareness of the investments' riskiness by the buyer and requires the removal of cognitive dissonance;

$\checkmark$ fourth, it is about the buyers' features, because, as a rule, the real estate purchase is a collective decision, etc.

Obviously, a complete rejection of personal sales in the construction industry is impossible and impractical.

\section{Conclusions and recommendations}


The complexity of using traditional marketing communication tools in construction is explained by a number of points:

$\checkmark$ the difficulty of the target audience to reach the television and radio advertising, - in fact, as a rule, the consumers initiate a search themselves if they are interested in acquiring real estate. Real estate is not a product of impulse purchases; therefore, advertising on television or radio is effective only if the buyer is already interested in purchasing an apartment, but if this has happened, then it is obvious that he has already taken a number of steps to find information from the most accessible source - the web. Consequently, advertising at these channels is reasonable on the start stage of construction process, when the information is not presented on the network yet, or when advertising has to stimulate a customer and to suggest a USP;

$\checkmark$ the difficulty of selecting an effective and at the same time unique method of sales promotion. Traditionally in the construction sector, price incentives are the most popular, but also they have limitations due to building products pricing. In addition, the use of price incentives usually begins at the time of sales stagnation, after the object's commissioning or at the final stage of its construction, which in a certain sense "corrupts" the consumer, forcing him to wait for maximum discounts. Mass use of price incentives at the final stage of construction, in conjunction with the new legislation on equity construction, can cause negative market trends in relation to the construction enterprise. That means that the sales will grow mainly after the object's commissioning, which will not allow the prompt repayment of the construction loan issued by banks - participants of the equity construction. However, the cost of marketing communications with the consumers should not be very high, otherways it will increase the cost of housing which is predicted to growth by no less than $10 \%$ anyway.

Thus, we can talk about the high reasonability of shifting the emphasis from traditional instruments of marketing communications to the field of Internet technologies for the following reasons:

$\checkmark$ the maximum broader target audience;

$\checkmark$ the possibility of pull-promotion technologies using;

$\checkmark$ the lack of time dependence on media broadcasting time;

$\checkmark$ the possibility of the object's visual representation;

$\checkmark$ the reduction of expenses for traditional expensive marketing communications and, as a result, the cost price and the final price of products;

$\checkmark$ the possibility of feedback from a potential/real buyer in the online mode;

$\checkmark$ the ability to a quick creation of a customer profile;

$\checkmark$ the possibility of rapid assessment of the communication's effectiveness. 
All the above allows us to talk about the high prospects for marketing activities on the Internet and the need to develop the marketing strategies for construction enterprises in implementing them into the global digital space.

\section{References:}

Dudin, M.N., Protsenko, I.O., Frolova, E.E., Posokhov, S.P., Voykova, N.A. 2017. Managing the Development of High-Tech Enterprises Based on Foresighting. Academy of Strategic Management Journal, 16(2).

Internet in Russia. 2018. Moscow, Printing house "Forward Print", 96 p.

Khairov, B.G., Novikov, D.T., Prokof'yeva, T.A., Protsenko, I.O., Khairova, S.M. 2017. Reflexive Governance of Import Substitution Mechanism in Clusters. European Research Studies Journal, 3(A), 471-483.

Khan, R.S., Surkov, V.V. 2015. About features of ensuring efficiency of marketing communications in the construction sphere. Engineering Journal of Don: Electr. scientific magazine, 4, Available at: http://www.ivdon.ru/en/magazine/archive/n4y2015/3324.

Khan, R.S., Surkov, V.V. 2017. Some features of building products brands. Scientific Journal Kant, 1(22), 192-195.

Terenina, I.V. 2006. Put in place. Supply chain management by creating virtual enterprises in the construction complex. Russian Entrepreneurship, 7, 92-96.

Terenina, I.V. 2016. Cluster approach to identifying risks in the supply chains. Russian Economic Internet Journal, 3.

Thalassinos, I.E., Thalassinos, Y. 2018. Financial Crises and e-Commerce: How Are They Related. Available at SSRN: https://ssrn.com/abstract=3330169.

Vasenev, S.L., Ovanesyan, N.M., Rossinskaya, M.V., Volgina, S.V., Rokotyanskaya, V.V. 2017. Crisis Management of Regional Development: Cluster Initiatives in Russia and their Efficiency. Journal of Advanced Research in Law and Economics, 2(8), Spring. 